\title{
APPLICATION OF A NOVEL ADSORBENT- AIRCRAFT TYRE RUBBER ASH FOR THE REMOVAL OF CHROMIUM FROM WASTEWATERS
}

\author{
Lakshmi Adathodii ${ }^{1 *}$, Raja Murugadoss $\mathrm{J}^{1}{ }^{1}$ and Kalyani Gaddam ${ }^{2}$ \\ ${ }^{1}$ Department of Civil Engineering, GMR Institute of Technology, \\ Rajam-532127, (Andhra Pradesh) India \\ ${ }^{2}$ Department of Chemical Engineering, GMR Institute of Technology, \\ Rajam-532127, (Andhra Pradesh) India \\ *E-mail: lakshmi.adathodi@gmail.com
}

\begin{abstract}
The eco-friendly and cost-effective technique of using tyre rubber waste for the removal of harmful toxic metals from wastewater will contribute a lot to the industry as well as the humanity from the environmental perspective. In the present work, an attempt has been made using aircraft tyre rubber waste carbon to remove the heavy metal chromium which is added to the water bodies through wastewater from various manufacturing industries. The batch study was performed to determine the removal efficiency by testing the effect of parameters such as contact time, dosage, initial concentration, $\mathrm{pH}$ of the solution and temperature. The amount of chromium ions removed from solution decreased rapidly from $\mathrm{pH} 3$ to $\mathrm{pH}$ 9. Increasing the adsorbent dose increased the percentage removal of chromium from $14.94 \%$ to $92.24 \%$. The removal efficiency of chromium using aircraft tyre rubber waste carbon was relatively fast (equilibrium time of 60 minutes). The removal efficiency of chromium decreased from 59.79\% to $49.02 \%$ with increasing concentration. The removal efficiency increased with an increase in temperature as well as an increase in dosage. The prepared adsorbent was characterized using Scanning Electron Microscope (SEM), Energy Dispersive X-ray Spectrometry (EDS / EDX) and X-ray diffraction (XRD) analysis to investigate the distinctive features of aircraft tyre rubber waste carbon. The results show that ATRWC has an excellent ability to remove chromium from the wastewaters.

Keywords: Aircraft tyre rubber waste carbon, Adsorption, Aqueous solution, Removal efficiency, Chromium
\end{abstract}

(c) RASĀYAN. All rights reserved

\section{INTRODUCTION}

In the recent era, the fast-moving world increased the growth of automobile industry which has boosted the tyre production which is being considered as the most problematic source for the generation of solid waste, due to the large volume produced and their durability. ${ }^{1}$ Globalization has contributed to the aviation industry to extend its passenger services connecting all possible places across the world. As a result, the frequency of landing and take-off of large aircraft has tremendously increased. Though the passenger services significantly increased on one side, it created a serious threat on the other side with more deposition of rubber at the time of landing and take-off. ${ }^{2}$ besides the economic growth, the solid waste generated by these tyres lead to high environmental pollution. Most of the tyre rubber waste is recycled to obtain value-added products for fuels, roads etc., but similar quantity is still discarded without proper treatment. ${ }^{3,22}$ The disposal of tyre rubber waste also involves expensive, dangerous transporting and storing facilities. ${ }^{4,23}$ Most of the tyre rubber waste is being sent to landfills or the open dumps, which raises a concern for the environmental pollution and social unrest. ${ }^{5,21}$ The scientific research has grown to recycle and reuse the tyre rubber waste from a few decades and one possible application is to prepare activated carbon for the removal of harmful pollutants from wastewater. The increase in the manufacturing industries has led to the rapid release of toxic metals into the aquatic ecosystems, thereby

Rasayan J. Chem., 11(3), 1204-1210(2018)

http://dx.doi.org/10.31788/RJC.2018.1134009

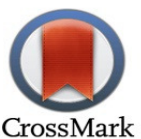


posing a hazard to the human health and the environment. The increased pollutants are found well above the threshold limits in the aquatic environment creating a great concern towards the protection of the ecosystem. ${ }^{6,7}$ Chromium is a well-known legendary pollutant being released from the manufacturing industries like tanneries, mining, cement ceramics and glass industries, manufacture of catalysts, fungicides, photography, pigments and paints, electroplating, production of steel and other metal alloys, photographic material and corrosive paints, chrome plating, etc., ${ }^{8,9}$ Chromium is released into the environment not only from natural sources but also from human activities. Chromium removal is of much concern because of its toxicity.

Thus, treatment of the effluent to reduce/remove the pollutant before discharging into the environment becomes inevitable. Adsorption is one of the most versatile and widely used techniques for the removal of toxic metals from the aqueous solutions. From more than three decades, activated carbon has been the water industry's standard adsorbent for the reclamation of municipal and industrial wastewater to make it possible for the potable usage..$^{10,11}$ A wide variety of materials such as chitosan, granular red mud ${ }^{12}$, sugar beet pulp ${ }^{13}$, rice husk ${ }^{14}$, rice bran ${ }^{15,16}$, activated carbon $^{17}$, Zeolite by Stylianou, Mimusops elengi ${ }^{18}$, sawdust, cocoa shells by Meunier, Sargassum ${ }^{19}$, Pithophora Cleveana Wittrock ${ }^{20}$ and leaves ${ }^{25}$ are examples of low-cost adsorbents used for the removal of heavy metals. The present study aims to assess the applicability of activated carbon derived from the aircraft tyre rubber waste for the removal of chromium from wastewaters to investigate the effect of operating parameters on the adsorption process. The parameters studied include contact time, initial chromium concentration, adsorbent dosage, initial solution $\mathrm{pH}$ and temperature. The results of the analysis could provide economical and effective technical support to full-scale industrial wastewater treatment plants with the utilization of aircraft tyre rubber waste.

\section{Reagents and Chemicals}

\section{EXPERIMENTAL}

The basic material used in the present study was sieved residual aircraft tyre rubber waste obtained from runways. Hydrogen peroxide $\left(\mathrm{H}_{2} \mathrm{O}_{2}\right)$, Potassium Dichromate $\left(\mathrm{K}_{2} \mathrm{Cr}_{2} \mathrm{O}_{7}\right)$, Nitric Acid $\left(\mathrm{HNO}_{3}\right)$ and other chemical reagents were obtained from different standard manufacturing industries. A metal solution of Chromium with different concentrations was prepared by dissolving the appropriate amount of Potassium Dichromate $\left(\mathrm{K}_{2} \mathrm{Cr}_{2} \mathrm{O}_{7}\right)$ in distilled water. $0.1 \mathrm{~N} \mathrm{NaOH}$ and $\mathrm{HCl}$ solutions were used for $\mathrm{pH}$ adjustment. In order to prevent metal contamination from laboratory glassware, glassware was kept overnight in a $10 \%$ (v/v) Nitric Acid $\left(\mathrm{HNO}_{3}\right)$ solution. All commercial chemical reagents were handled very carefully and storage was also in compliance with the recommendations. A digital $\mathrm{pH}$ meter (Orion make) was used for all $\mathrm{pH}$ measurements. A high precision electrical balance was used for weighing. Continuous mixing was provided during the experimental period with a constant agitation speed for better mass transfer with a high interfacial area of contact.

\section{Instrumentation}

i. Orbital shaker (REMI-CIS-24plus model): to agitate the metal solutions with adsorbents

ii. Muffle Furnace $(3.5 \mathrm{KW}, 230 \mathrm{~V}, 50 \mathrm{~Hz})$ : to activate the tyre rubber powder

iii. $\mathrm{pH}$ Meter with a glass electrode (335A, Systronics, Ahmadabad, S. No.: 7898): to measure the $\mathrm{pH}$ of the metal solutions

iv. Filter paper (Whatman-42): to filter the metal solutions and the adsorbent mixture

v. Analytical Balance (Shimadzu, AUX220): to weigh the adsorbents

vi. UV-Visible Spectro photometer (Double beam): to determine the absorption of light from a sample and can be used as a detector for High-performance liquid chromatography (HPLC)

\section{Preparation of Adsorbent}

Activated carbon was prepared from aircraft tyre rubber waste via carbonization, chemical treatment, and steam activation. The rubber waste powder was cleaned, thoroughly washed with deionized water, and then dried in an oven at $100^{\circ} \mathrm{C}$ for $4 \mathrm{~h}$. For carbonization, the dried material was heated to approximately $120^{\circ} \mathrm{C}$ for $24 \mathrm{~h}$. This was followed by treatment with $30 \%$ hydrogen peroxide $\left(\mathrm{H}_{2} \mathrm{O}_{2}\right)$ solution for $2 \mathrm{~h}$ to oxidize adhering organic impurities. The material was washed with deionized water and dried in a 
vacuum oven at $60^{\circ} \mathrm{C}$ for $24 \mathrm{~h}$. The dried material was activated to $500^{\circ} \mathrm{C}$ for $2 \mathrm{~h}\left(\mathrm{~N}_{2}\right.$ flow $0225 \mathrm{~mL} \mathrm{~min}^{-}$ $\left.{ }^{1}\right)$. Then, it was removed from the furnace and cooled in a desiccator. The material was then treated with 4 $\mathrm{M}$ nitric acid solution to remove the ash content and was then washed with deionized water. The product was finally dried in an oven at $120^{\circ} \mathrm{C}$ for $24 \mathrm{~h}$.

\section{Characteristics of Adsorbent Material}

The physical properties and chemical composition of the Aircraft tyre rubber are presented below. The morphological characteristics of the adsorbent were evaluated by using a Phillips XL30 SEM, and the chemical composition was justified by performing EDS / EDX and XRD analysis.

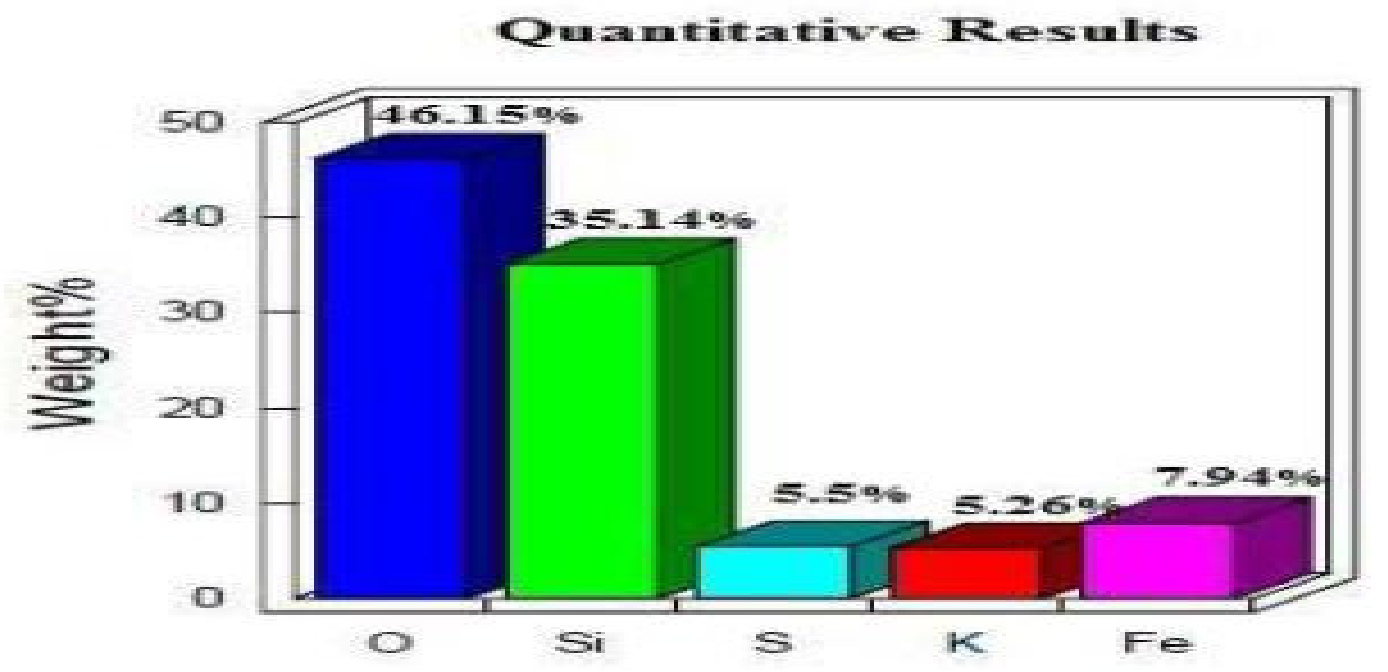

Fig.-1: Chemical Analysis of Waste Tire Rubber Ash

\section{Batch Adsorption Experimental Studies}

The adsorption studies were conducted in exploratory conditions of various effective process parameters of $\mathrm{pH} 3-9$, contact time 60-120 min, metal ion concentration ranges 50ppm-150ppm, the dosage of the adsorbent $0.25 \mathrm{~g}-0.75 \mathrm{~g}$ and the temperature $25^{\circ} \mathrm{C}-35^{\circ} \mathrm{C}$. The agitation speed of $350 \mathrm{rpm}$ was kept constant in the orbital shaker with the suitable time interims. The mixed adsorbent solutions were taken out and filtered by Watmann filter paper and analyzed for metal ion concentration in a UV-Visible Spectro-photometer (Double beam). Batch experiments were conducted by changing the parameters like contact time, initial chromium concentration, adsorbent dosage, initial solution $\mathrm{pH}$ and temperature by utilizing orbital shaker from 303K - 323K. Samples were analyzed by UV-Visible Spectro-photometer.

\section{Effect of pH}

\section{RESULTS AND DISCUSSION}

It is well known that the removal of heavy metals by adsorbent depends on the $\mathrm{pH}$ of the initial solution. Therefore, in order to establish the effect of $\mathrm{pH}$ on the adsorption of chromium ions, the batch equilibrium studies were carried out at different $\mathrm{pH}$ values. The $\mathrm{pH}$ range was chosen 3-9. The $\mathrm{pH}$ of the solution was adjusted by using $0.1 \mathrm{~N} \mathrm{HCl}$ and $0.1 \mathrm{~N} \mathrm{NaOH}$ and prepared tyre rubber adsorbent were added to $100 \mathrm{ml}$ of solution in $250 \mathrm{ml}$ flasks. The adsorbent was thoroughly mixed with the help of magnetic shaker for 90 minutes and the adsorbent mixture was filtered using Whatman filter paper. The prepared standard solutions along with the filtered adsorbent mixture were tested for the chromium. The progress of adsorption was assessed by determining the residual concentration of $\mathrm{Cr}$ in the supernatant by the UV-Vis Spectrophotometer. Figure-2 shows the amount of chromium ions removed from aqueous solution as a function of $\mathrm{pH}$ at a $\mathrm{Cr}$ concentration of $100 \mathrm{mg} / \mathrm{L}$. The amount of chromium ions removed from solution

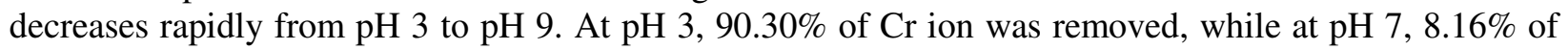
$\mathrm{Cr}$ ion was removed and at $\mathrm{pH} 9$, the amount of chromium ion removed from the solution by the aircraft tyre rubber adsorbent steadily decreased to $5.93 \% .^{26}$ 


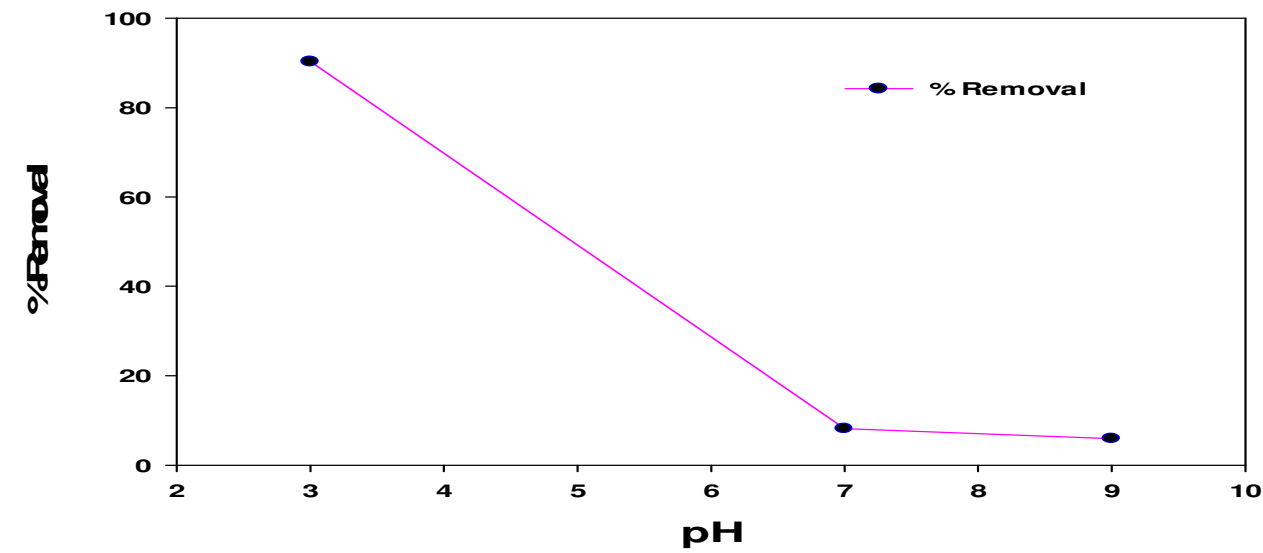

Fig.-2: Effect of $\mathrm{pH}$ on the Removal of Chromium by Aircraft Tyre Rubber Carbon: $100 \mathrm{~mL}$ of solution, 0.5 $\mathrm{g} / 100 \mathrm{ml}$ of Adsorbent, 100ppm Concentration,Temperature $30^{\circ} \mathrm{C}$, time $90 \mathrm{~min}, \mathrm{pH} 3,7$ and 9

\section{Effect of Adsorbent Dose}

To determine the capacity of an adsorbent for a given initial concentration of metal ion solution, dosage study is an important parameter which determines the capacity of an adsorbent. The effect of adsorbent dose on the percent removal of chromium at the concentration of $100 \mathrm{ppm}$ is shown in below Fig.3. From the Fig.2, it can be observed that increasing the adsorbent dose increased the percent removal of chromium from $14.94 \%$ up to $92.24 \%$ with the required optimum dose of $0.75 \mathrm{~g} / 100 \mathrm{ml}$ of chromium solution. As expected, the removal efficiency increased with increasing the adsorbent dose for a given initial metal concentration, because, for a fixed initial adsorbate concentration, increasing adsorbent dose provides a greater surface area or more adsorption sites. Further, it can be attributed to the binding of metal ions onto the surface functional groups present on the Aircraft tyre rubber carbon. On the other hand, when the rubber carbon dose increased more than the limit, the adsorption capacity (the amount adsorbed per unit mass of adsorbent) decreased. The decrease in adsorption capacity with an increase in the adsorbent dose is mainly due to the increase of free adsorption sites in the adsorption reaction.

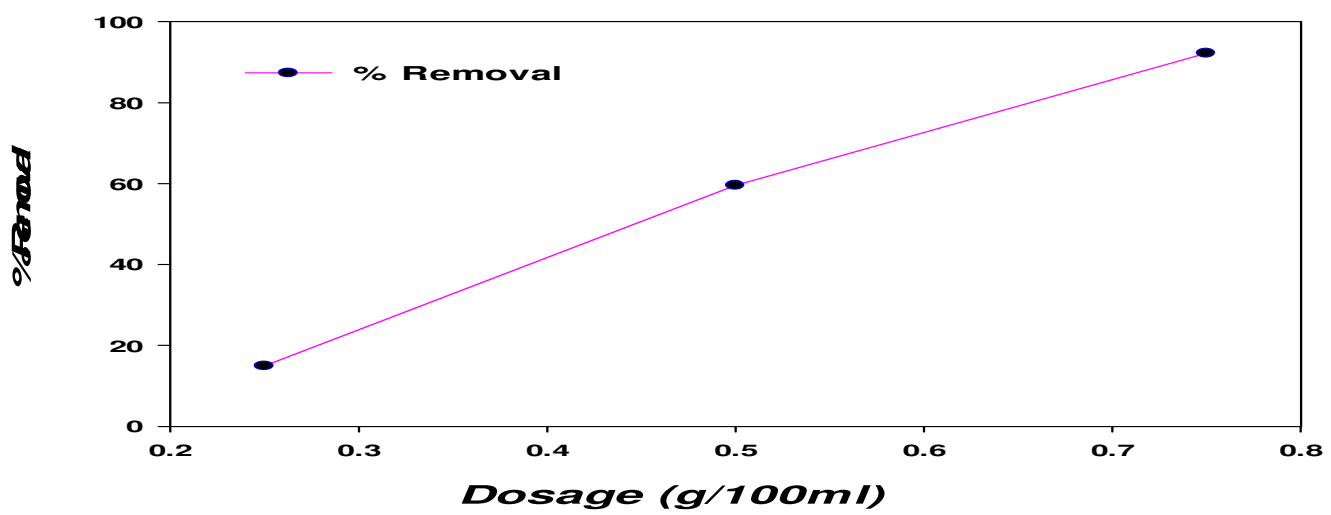

Fig.-3: Effect of Adsorbent Dosage on the Removal of Chromium by Aircraft Tyre Rubber Carbon: $100 \mathrm{~mL}$ of Solution, $\mathrm{pH} 3,100 \mathrm{ppm}$ Concentration, Temperature $30^{\circ} \mathrm{C}$, Time $90 \mathrm{~min}$, and $0.25,0.5$ and $0.75 \mathrm{~g} / 100 \mathrm{ml}$ of Adsorbent.

\section{Effect of Contact Time on the Removal of Chromium}

The effect of contact time for the Cr removal at the condition of $0.5 \mathrm{~g} / 100 \mathrm{ml}$ solution of the adsorbent, optimal pH 3.0, the initial concentration of $100 \mathrm{ppm}$ with a temperature of $30{ }^{\circ} \mathrm{C}$ and the contact time of $60 \mathrm{~min}$. As indicated in Fig.4. the Cr removal efficiency was decreased slowly up to $90 \mathrm{~min}$ and then it reached very lower level right after $60 \mathrm{~min}$. The sharp decrease in the removal efficiency may be due to the existence of enormous vacant active sites on the adsorbent surface. However, by raising the contact 
time the availability of $\mathrm{Cr}$ ions to the active sites on the adsorbent surface is limited, which results in low removal efficiency. In a further related study, ${ }^{27}$ reported that the adsorption of $\mathrm{Cr}$ on nano-carbonate hydroxyl apatite reached the equilibrium state at $90 \mathrm{~min}$ at different concentrations of Cr. Since $90 \mathrm{~min}$ is more than the optimal time obtained in the present study, it can be noted that the Aircraft tyre rubber carbon has higher adsorption rate than nano-carbonate hydroxyl apatite.

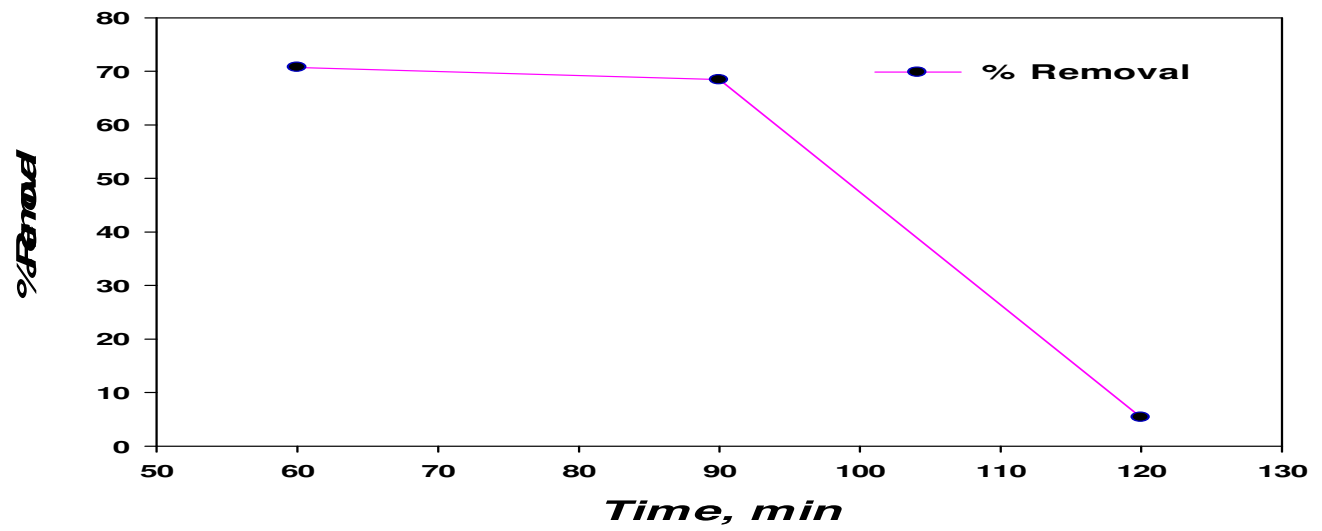

Fig.-4: Effect of Contact Time for the Removal of Chromium by Aircraft Tyre Rubber Carbon: $100 \mathrm{~mL}$ of Solution, $\mathrm{pH} 3,100 \mathrm{ppm}$ Concentration, Temperature $30^{\circ} \mathrm{C}$, Contact time $60 \mathrm{~min}, 90 \mathrm{~min}$ and $120 \mathrm{~min}$.

\section{Effect of Concentration of Solution}

The concentration of the solution changes the percent removal of metal ions from aqueous solution. The effect of concentration was calculated by changing the concentration of the solution as $50 \mathrm{ppm}, 100 \mathrm{ppm}$ and $150 \mathrm{ppm}$ at $30{ }^{\circ} \mathrm{C}$ with the contact time of $90 \mathrm{~min}, \mathrm{pH} 3$ and adsorbent dosage of $0.5 \mathrm{~g} / 100 \mathrm{ml}$ of solution. Results mentioned in the Fig.5. Explained that the removal efficiency decreased with increasing the concentration of the metal ion solution. ${ }^{27}$

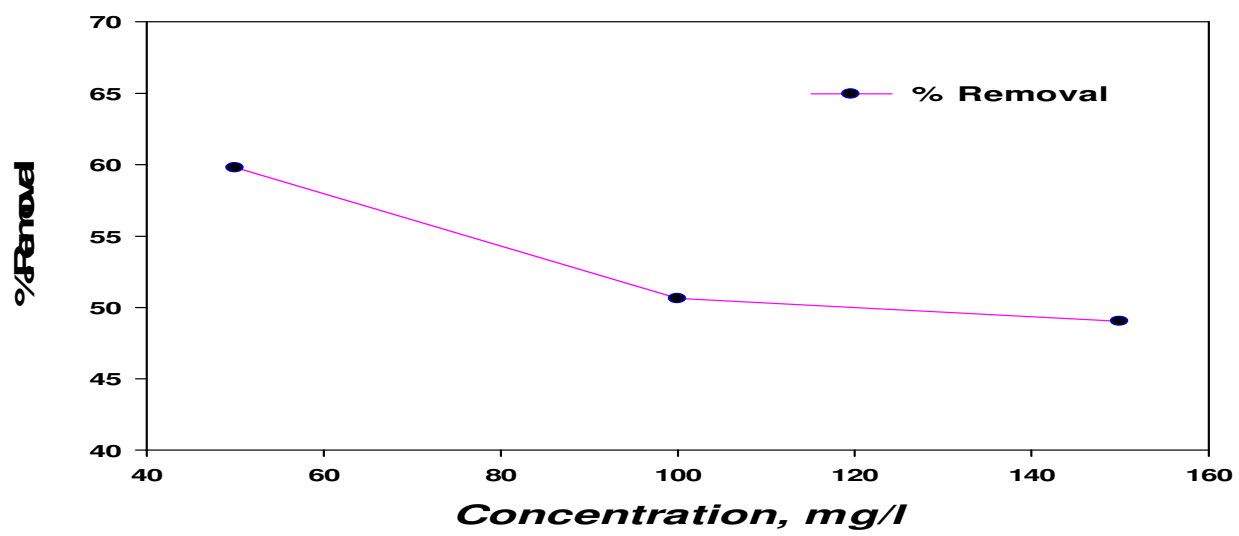

Fig.-5: Effect of Concentration for the Removal of Chromium by Aircraft Tyre Rubber carbon: $100 \mathrm{~mL}$ of Solution, $\mathrm{pH} 3$, Temperature $30^{\circ} \mathrm{C}$, Contact time $90 \mathrm{~min}$, Concentration 50ppm, 100ppm and $150 \mathrm{ppm}$.

\section{Effect of Temperature on Removal of Chromium}

To determine whether the ongoing adsorption process was endothermic or exothermic in nature, chromium adsorption studies using Aircraft tyre rubber carbon were carried out between $25^{\circ} \mathrm{C}-35^{\circ} \mathrm{C}$ for the initial feed concentration and at a constant adsorbent dose of $0.5 \mathrm{~g} / 100 \mathrm{ml}$ solution. It can be observed from Fig.6.that the adsorption of chromium ions increased when the temperature was increased up to a certain temperature i.e., at $25^{\circ} \mathrm{C}$ the amount of $\mathrm{Cr}$ ion removed was $9.34 \%$, whereas, at $30^{\circ} \mathrm{C}$, $79.47 \%$ of $\mathrm{Cr}$ ion was removed by rubber carbon for an initial concentration of $100 \mathrm{ppm}$. It can be seen from the figure that, initially, the percentage removal increased sharply with the increase in temperature, but beyond a certain value of $30^{\circ} \mathrm{C}$, the percentage removal decreased to a minimum value. These results 
showed that the sorption was endothermic in nature upto a certain point. ${ }^{27}$ The increased sorption with the rise of temperature may be diffusion controlled, which is an endothermic process, i.e., the rise in temperature favors the sorbate transport within the pores of sorbent.

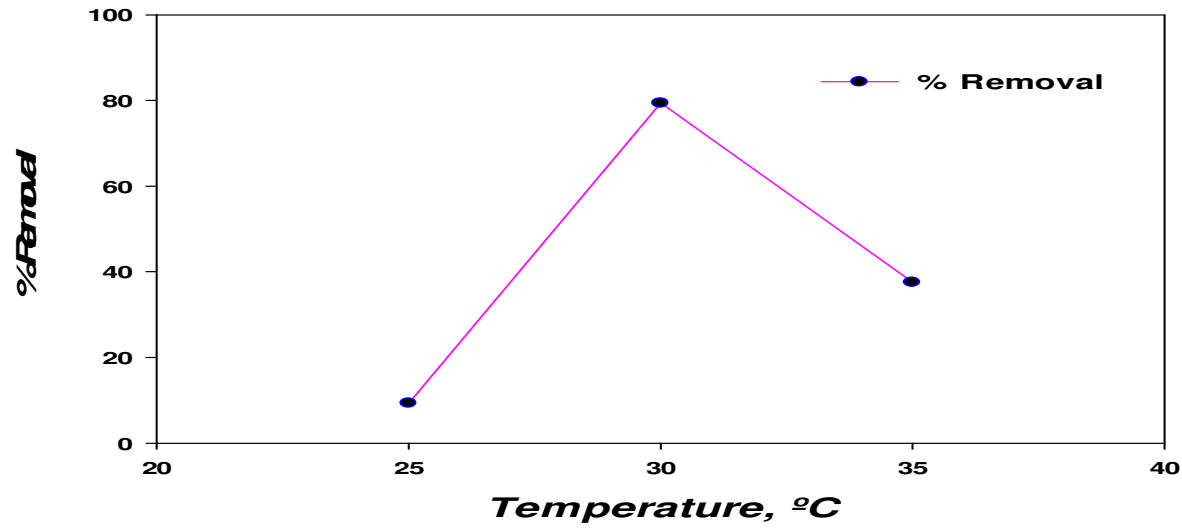

Fig.-6: Effect of Temperature for the Removal of Chromium by Aircraft Tyre Rubber Carbon: $100 \mathrm{~mL}$ of Solution, $\mathrm{pH} 3$, Contact time $90 \mathrm{~min}$, Concentration $100 \mathrm{ppm}$, Temperature $25^{\circ} \mathrm{C}, 30^{\circ} \mathrm{C}$ and $35^{\circ} \mathrm{C}$

\section{Effect of Optimum Conditions}

Functionalized activated Carbon derived from Aircraft tyre rubber was investigated for the adsorption of chromium from aqueous solutions. It was demonstrated in this study that aircraft tyre rubber carbon could be used as an effective adsorbent for $\mathrm{Cr}$ and optimum conditions were found. The equilibrium time is 60 min for the adsorbent having a concentration of $50 \mathrm{ppm}$. The maximum adsorption takes place at the $\mathrm{pH}$ of 3.0 with the temperature of $30^{\circ} \mathrm{C}$.

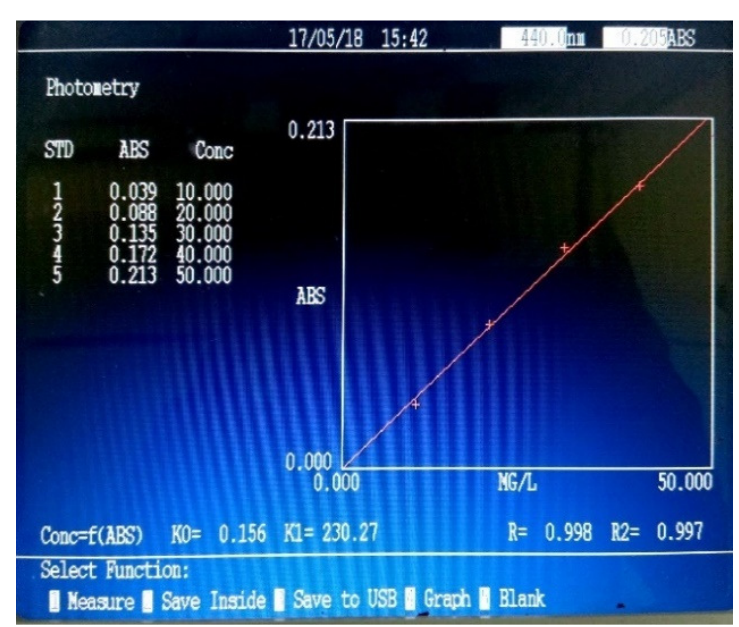

Fig.-7: Concentration for Standard Solution

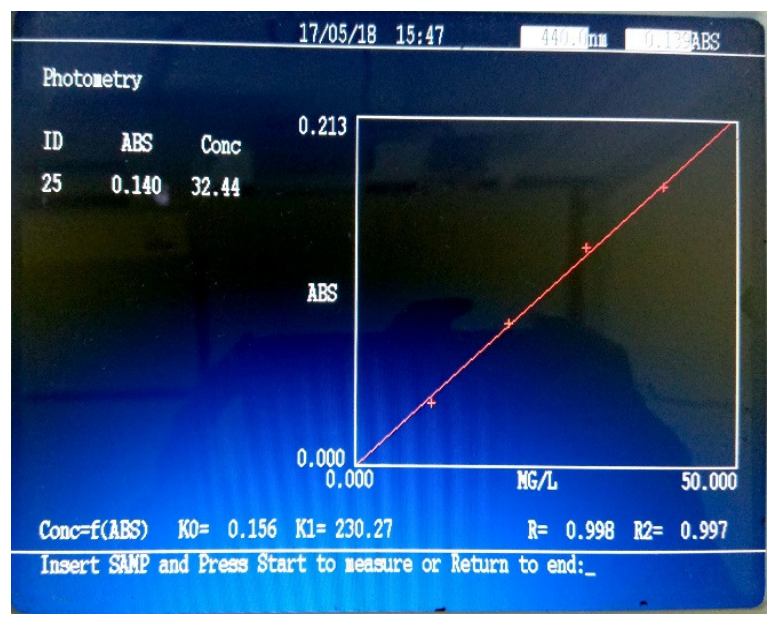

Fig.-8: Optimum Removal Efficiency for Cr Metal Ion

Table-1

\begin{tabular}{c|c|c}
\hline Parameter & Optimum Point & $\begin{array}{c}\text { Cr removal } \\
\text { Efficiency } \%\end{array}$ \\
\hline $\mathrm{pH}$ & 3.0 & 90.30 \\
Dosage & $0.75 \mathrm{~g}$ & 92.24 \\
Concentration & $50 \mathrm{ppm}$ & 59.79 \\
Contact time & 60 minutes & 70.75 \\
Temperature & $30^{\circ} \mathrm{C}$ & 79.47 \\
\hline
\end{tabular}

CONCLUSION 
In the present study, the removal efficiency of chromium from wastewaters using ATRWC was investigated in a batch system. Characterization using Scanning Electron Microscope (SEM), Energy Dispersive X-ray Spectrometry (EDS / EDX) and X-ray diffraction (XRD) was done to confirm the chemicals present in the prepared ATRWC. The following conclusions can be drawn.

The resulted removal efficiency by setting the obtained optimum parameters was $67.56 \%$. The obtained result can be stated as a good investigation for the possibility of the utilizing the ATRWC as a low cost adsorbent for removal of chromium from wastewaters.

\section{REFERENCES}

1. D.L. Presti, Const \& Building Materials., 49(2), 863 (2013)

2. A. Lakshmi, J. Raja Murugadoss, and S. Naveen Kumar, Int J. of Civi.l Engg\& Tech., 9(2), 275 (2018)

3. G. Vinod Kumar and Imran Ali, Env Sci. Poll Res., 20, 1261 (2013)

4. A. Lakshmi, J. Raja Murugadoss, and G. Kalyani, Int. J. of Mech \& Pro. Engg Res\& Dev., 8(2), 1227 (2018)

5. G. Kalyani, Y. Prasanna Kumar, and P. King, Rasayan J. of Chem., 9(3), 510 (2016)

6. N. Tewari, P. Vasudevana, and B.K. Guha, Bio Chem. Engg., 23, 185 (2005), DOI:10.1016/j.bej.2005.01.011

7. C. Raji and T. S. Anirudhan, Wat. Res. Engg., 32, 3772 (2005)

8. H. Z. Mousavi1, A. Hosseynifar, and V. Jahed, Bra. J. of Chem. Engg., 27, 79 (2010)

9. H. Joga Rao, P. King, and Y. Prasanna Kumar, Rasayan J. of Chem., 9(2), 254 (2016)

10. H. Panda, N. Tiadi, and C.R. Mohanty, SA. J. of Chem. Engg., 23, 132 (2017)

11. Z. Chunlei and Zhaokun Luana., J. of Separ. \& Pur. Tech., 57, 161 (2017)

12. M. Madhavi and B. Mansor, J. of Bio. Res., 6, 22 (2017)

13. K.K. Wong, C.K. Lee, and K.S. Low, J. of Chem., 50, 23 (2003)

14. S.F. Montanher, E.A. Oliveira, and M.C. Rollemberg, J. of Haz. Mat., 117, 207 (2005), DOI: 10.1016/j.jhazmat.2004.09.015

15. M. Ajmal, A. Rao, and S. Anwar, J. of Bio Res tech., 86, 147 (2003)

16. L. Giraldo1 and J. C. Moreno-Piraján, Bra J. of Chem. Engg., 25, 143 (2008)

17. G. Kalyani, Y. Prasanna Kumar, and P. King, Res J. of Phar. Bio. \& Chem. Sci., 7, 1586 (2016)

18. A. Fatemeh, H. Shariatmadari, and N. Mirghaffari, J. of Haz. Mat., 154, 451 (2008)

19. G. Kalyani, Y. Prasanna Kumar, and P. King, Int. J. of Cur. Res., 8, 26048 (2016)

20. A. Ali, K. Saeed, and F. Mabood, J. of Alex Engg., 55, 2933 (2016), DOI: 10.1016/j.aej.2016.05.011

21. S. Saroj Baral, N. Surendra, and R. Pradip, J. of Bio. Chem. Engg., 23, (2005)

22. Z. Chunlei, L. Zhaokun, and Y. Wang, J. of Sep. \& Puri. Tech., 57, 161 (2007)

23. F. Gode and Pahlivan, J. of Haz. Mat.,, 136, 330 (2006)

24. K. Wong and K.S. Haron, J. of Chem., 50, 23 (2003)

25. P.N. Nomngongo and J.C. Ngila, J. of Fuel Engg., 139, 285 (2015)

26. T. Wen Qing, R. Ying, and Y. Lan, J. of Chem Engg.,, 223, 340 (2013)

[RJC-4009/2018] 